Check for updates

Cite this: RSC Adv., 2017, 7, 40803

\title{
Cage to cage study of ionic liquid and cyclic oligosaccharides to form inclusion complexes $\uparrow$
}

Received 30th July 2017

Accepted 15th August 2017

DOI: 10.1039/c7ra08397a

rsc.li/rsc-advances

\begin{abstract}
Aditi Roy (D) and Mahendra Nath Roy*
The inclusion complexation behaviour, characterization and binding ability of trihexyltetradecylphosphonium chloride with $\alpha$ and $\beta$-cyclodextrin have been investigated both in aqueous solution and solid state by means of ${ }^{1} \mathrm{H}$ NMR, surface tension, conductivity, density, viscosity, refractive index, FTIR and HRMS measurements. The shifts in the NMR spectra reveal that part of the ionic liquid is inserted into the cyclodextrin molecules. Surface tension and conductivity studies approve the 1:1 stoichiometry of the inclusion complex while density, viscosity and refractive index measurements show the interaction of the ionic liquid with the host molecules. FTIR and HRMS studies confirm the inclusion phenomenon. Binding constants have been evaluated using a non linear programme and NMR study, indicating a higher degree of encapsulation in the case of $\beta$-cyclodextrin compared to $\alpha$-cyclodextrin.
\end{abstract}

\section{Introduction}

The field of Ionic liquids draws the attention of modern chemists because of their unusual properties such as low vapour pressure, high thermal and chemical stability, large liquid temperature range and high solvation ability towards inorganic, organic, complex salts and biopolymers. ${ }^{1}$ These properties make them completely different from molecular liquids. Ionic liquids generally constitute a large organic cation and a small anion. ${ }^{2}$ They have vast applications in various chemical industries because of their green nature. They produce less hazardous compounds during their use. ${ }^{3}$ Phosphonium based ionic liquids are less toxic and more thermally stable than nitrogen based ionic liquids. ${ }^{1}$ In this research article the phosphonium based hydrophobic ionic liquid Trihexyltetradecylphosphonium chloride (TTP) (Scheme 1) has been used. This ionic liquid is highly used in separation of different dyes including methylene blue from aqueous media. This has also application as additives to improve the yield of essential oils in the hydrodistillation process. $^{4}$

Cyclodextrin (CD), a cyclic oligosaccharide, is well known in supramolecular chemistry as molecular host because of their ability of inclusion of a range of guest molecules through non covalent interaction in their hydrophobic cavity. ${ }^{5} \alpha, \beta$ and $\gamma$ cyclodextrins consists of 6,7 and 8 glucose units respectively linked by $\alpha-1,4$ glucosidic linkage. ${ }^{6}$ They can be described as

Department of Chemistry, University of North Bengal, Darjeeling-734013, India. E-mail: mahendraroy2002@yahoo.co.in; Fax: +91 353 2699001; Tel: +91 3532776381 $\dagger$ Electronic supplementary information (ESI) available: Theory and tables (Tables S1-S9) have been provided. See DOI: 10.1039/c7ra08397a a shallow truncated cone having primary and secondary hydroxyl groups in the rims (Scheme 2). ${ }^{5}$ They can form stable inclusion complex with drugs, vitamins, ionic liquids, amino acids, neurotransmitters etc. guest molecules. ${ }^{7}$ The weak intermolecular forces acting between the guest and host includes van der Waal's force, dipole-dipole interaction, electrostatic and hydrogen bonding interactions. ${ }^{8} \mathrm{CD}$ 's are non-toxic and considered safe to humans. Formation of inclusion complex is the best method to improve the physicochemical properties of the guest molecule. Due to the enormous application of the inclusion complexes formed by them they are used in cosmetic, food and pharmaceutical industeries. ${ }^{9}$

In the present study we attempt to ascertain the formation and nature of IC of $\alpha$ and $\beta$-CD with TTP in aqueous environment by spectroscopic and physicochemical studies. Our aim is to explore the formation, carrying and controlled release of this ionic liquid by forming IC with CD without any chemical and biological modification of the guest molecule. Thus it will find better utility in the dye industry and also in the hydrodistillation process of oils. To the best of our knowledge no theoretical investigation concerning inclusion complex formation between $\alpha$ and $\beta$-CD and TTP has been performed so far.

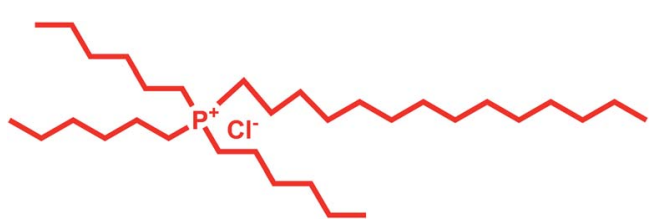

Scheme 1 Two dimensional molecular structure of the ionic liquid trihexyltetradecylphosphonium chloride. 


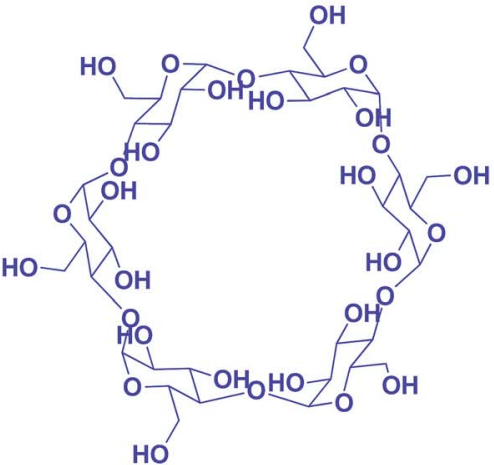

$\alpha-C D$

(a)

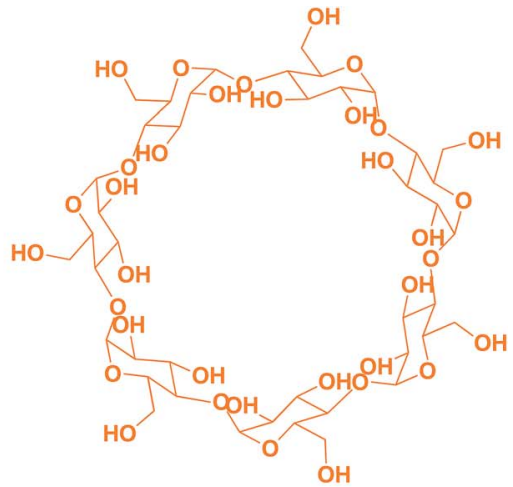

$\beta-C D$

(b)

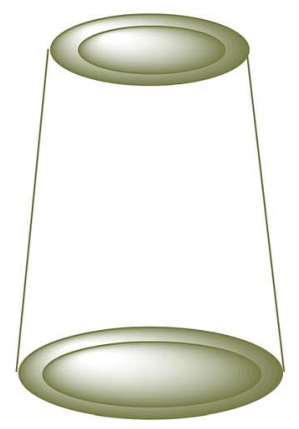

(c)

Scheme 2 Structure of (a) $\alpha-C D$ (b) $\beta-C D$ and (c) cone structure of cyclodextrin molecule.

\section{Results and discussions}

\section{1. ${ }^{1} \mathrm{H}$ NMR spectra}

${ }^{1} \mathrm{H}-\mathrm{NMR}$ study confirms the formation of inclusion complex of TTP with $\alpha$ and $\beta$-CD. ${ }^{9,10}$ Insertion of ionic liquid molecule into the hydrophobic cavity of $\mathrm{CD}$ molecules consequences the chemical shift of both the guest and host molecule. The TTP molecule results dimagnetic shielding of the protons as a result of interaction with the CD protons after inclusion. The position of different protons in the CD molecules are shown in Scheme 3 . The $\mathrm{H} 3$ and $\mathrm{H} 5$ protons are situated inside the cavity

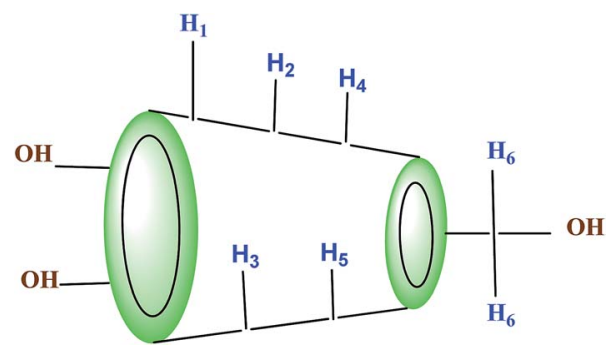

Scheme 3 Location of different protons in truncated conical structure of $\alpha$ and $\beta$-cyclodextrin. near the wider rim and narrower rim respectively. The other protons $\mathrm{H} 1, \mathrm{H} 2$ and $\mathrm{H} 4$ are situated outside the $\mathrm{CD}$ molecule. ${ }^{11,12}$ The respective $\delta$ values of the ionic liquid TTP, $\alpha-\mathrm{CD}$, $\beta$-CD and inclusion complexes are reported in Table S1. $\dagger$ The protons of CD and TTP show considerable upfield shift in $1: 1$ inclusion complex of the ionic liquid and CD (Fig. 1 and 2). It can be concluded from chemical shift that the protons of the hydrocarbon chain of TTP interacts more with the H3 protons than $\mathrm{H} 5$ suggesting the TTP molecule enters in the hydrophobic cavity from wider end. The shift in $\delta$ value of both the CD perhaps due to change of environment after inclusion complex formation. The H6 proton of $\alpha$ and $\beta$-CD remain uneffected after inclusion which again supports the fact that the guest molecule inserts from wider end (Scheme 4).

\subsection{Surface tension study}

The formation and stoichiometry of the inclusion complexes can be interpreted with surface tension study. ${ }^{13,14}$ Adding CD to water does not change the surface tension $(\gamma)$ of water as it is hydrophobic in nature. This fact also illustrates that $\mathrm{CD}$ is surface inactive compounds. ${ }^{15}$ The ionic liquid TTP contains many long hydrocarbon chains and acts as strong surface active agent. The $\gamma$ value of TTP is lower than pure water. Here the $\gamma$ 


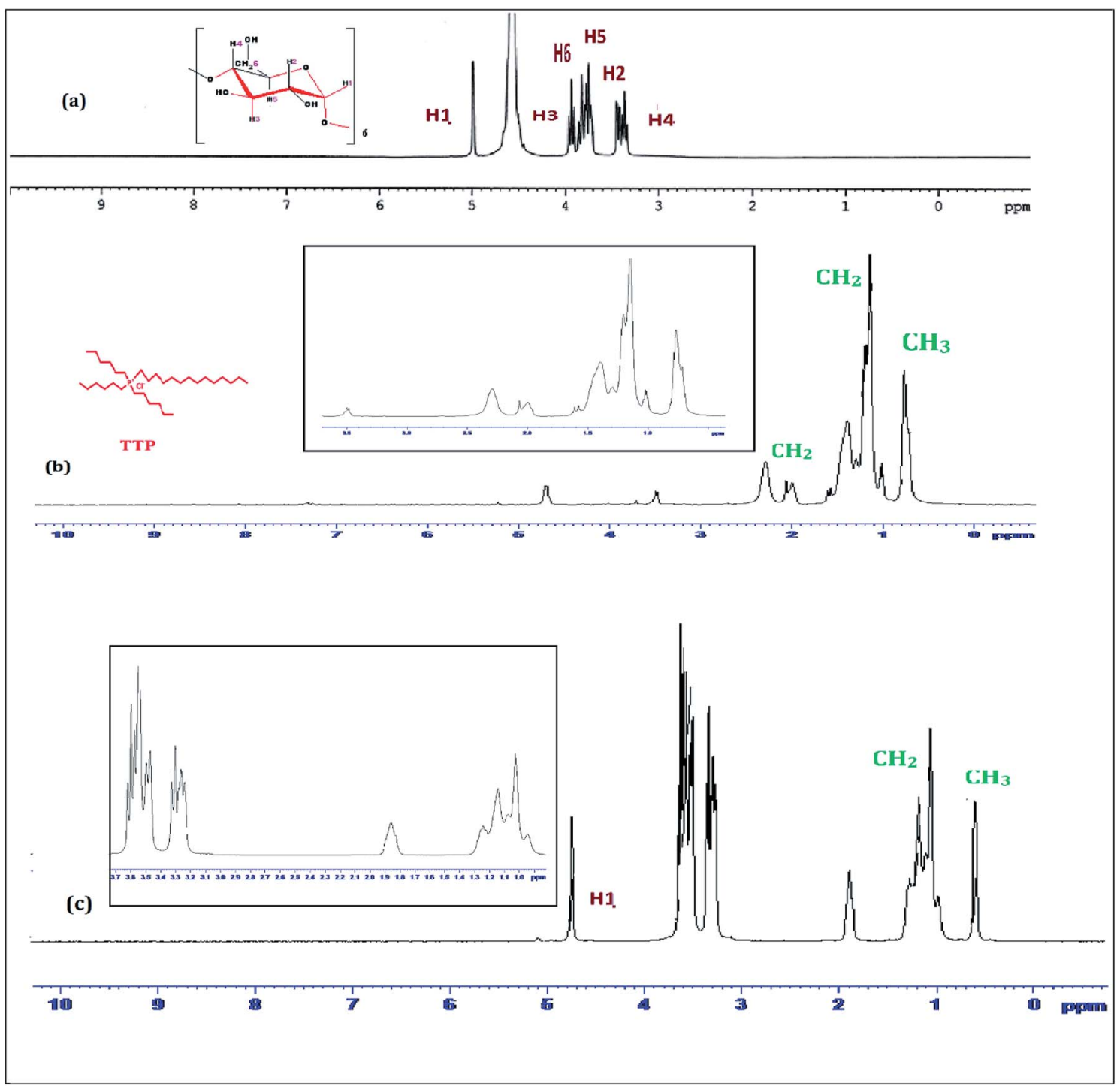

Fig. $1{ }^{1} \mathrm{H}$ NMR spectra of (a) $\alpha-C D$ (b) TTP and (c) $1: 1$ molar ratio of $\alpha-C D+$ TTP in $D_{2} \mathrm{O}$ in $298.15 \mathrm{~K}$.

value of a series of solutions of TTP with increasing concentration of $\alpha$-CD and $\beta$-CD have been measured at 298.15 K (Tables S4 and S5 $\dagger$ ). The $\gamma$ value is found to increase for both the CD molecules. This is probably due to insertion of the hydrocarbon chain of the ionic liquid from the solution to the hydrophobic cavity of the host CD molecules. A single distinguishable break appears in the two surface tension plots depicted in Fig. 3 which suggests the formation of IC. ${ }^{16,17}$ The concentrations of TTP and the CD molecules at the break point (Table 1 ) is approximately $1: 1$ which further confirms the stoichiometric ratio of the two ICs as $1: 1$. More number of breaks in the plot suggests complex stoichiometry of the complex such as $1: 2,2: 1,2: 2$ etc. The surface tension at the break point is slightly higher for $\beta$-CD indicating it a better host compared to $\alpha$-CD.

\subsection{Conductivity study}

Conductivity study also supports the formation and stoichiometry of the two inclusion complexes formed. ${ }^{18,19}$ The aqueous solution of the ionic liquid TTP shows considerable conductivity as it exists as a charged structure. In this study the conductivity of a series of solutions of TTP with increasing concentration of $\alpha-C D$ and $\beta-C D$ have been measured at 298.15 K (Tables S4 and S5 $\dagger$ ). The conductivity value shows regular decrease and after a sharp break point the conductivity value almost becomes constant. Similar results obtained in case of both host CD molecules. The decrease in the $\kappa$ value probably due to the encapsulation of the long hydrocarbon chain of the guest TTP molecules in the hydrophobic cavity of CD. The values of $\kappa$ and corresponding concentration of the host CD molecules are reported in Table 1 which suggests that the ratio of concentration of TTP and the CD at the break point is almost $1: 1$. The appearance of sharp break (Fig. 4) points suggest the formation of inclusion complex and also the stoichiometry as $1: 1 .^{20}$

The break point indicates certain concentration where maximum number of TTP molecules are inserted in CD 


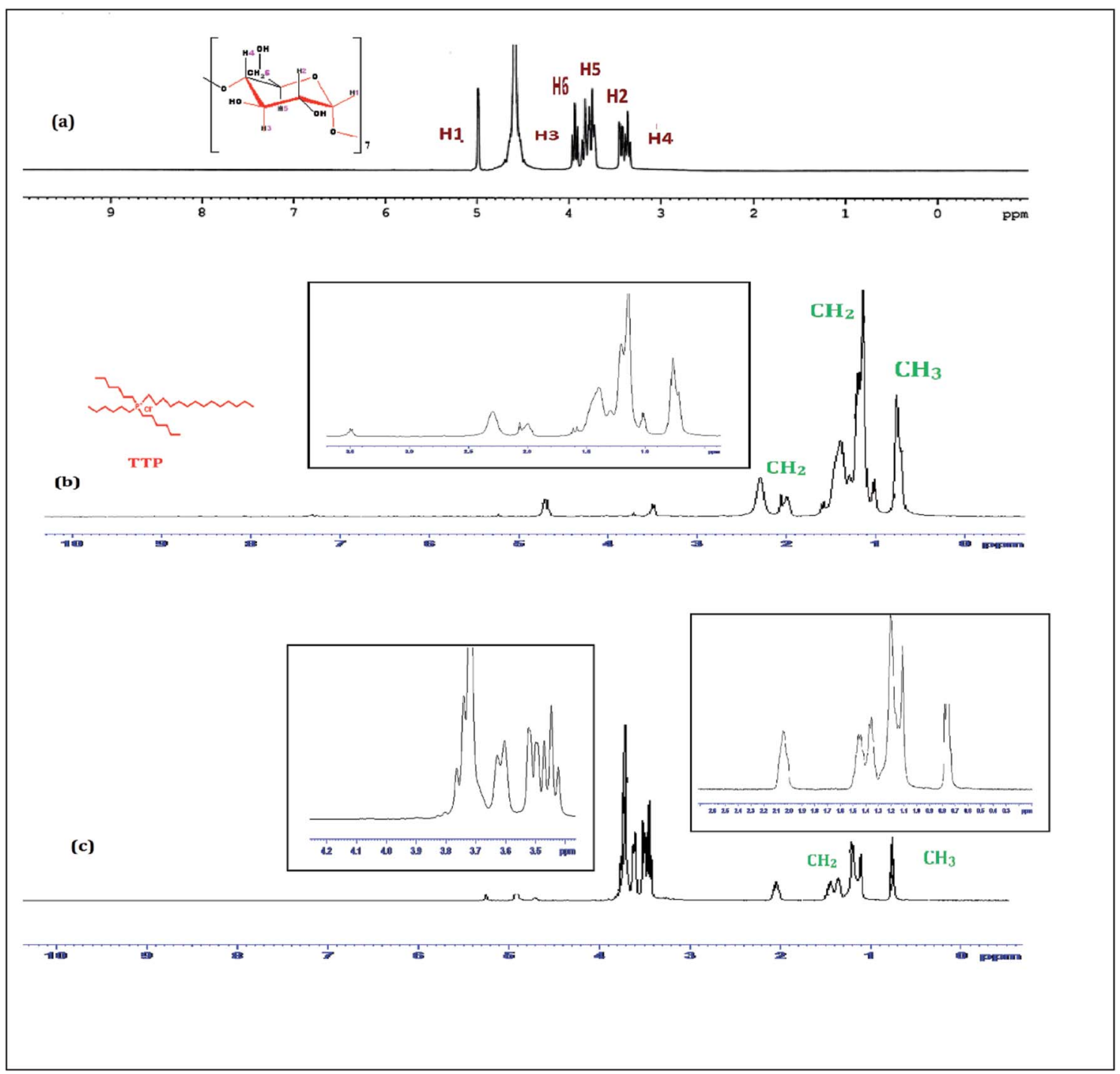

Fig. $2{ }^{1} \mathrm{H}$ NMR spectra of (a) $\beta-C D$ (b) TTP and (c) $1: 1$ molar ratio of $\beta-C D+$ TTP in $D_{2} \mathrm{O}$ in $298.15 \mathrm{~K}$.

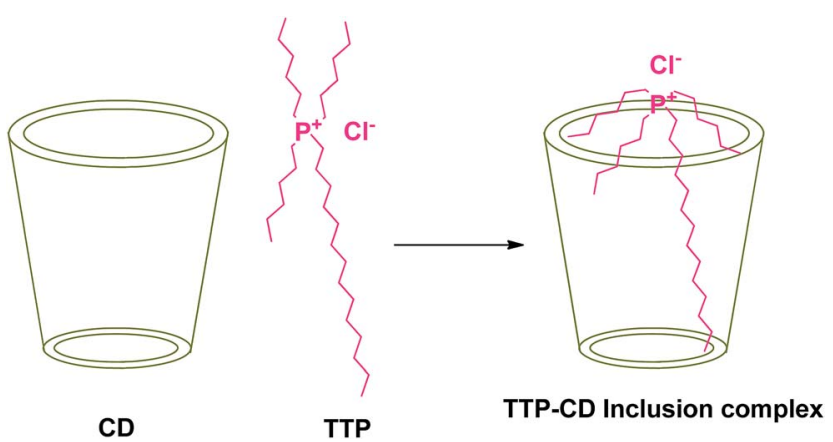

Scheme 4 Plausible mechanism of formation of inclusion complex between TTP and CD molecule.

molecule ever before. ${ }^{11} \mathrm{~A}$ dynamic equilibrium exsists between the guest ionic liquid and host CD molecules

Ionic liquid + cyclodextrin $\rightleftharpoons$ inclusion complex
Maximum inclusion takes place at break point, after it the concentration of CD is higher than the concentration of TTP and the equilibrium shifts more towards the formation of IC.

\subsection{Density study: illustrates the interaction}

The interaction between the ionic liquid and the host molecules can be nicely explained with the help of density study. The apparent molar volume $\left(\varphi_{\mathrm{v}}\right)$ and limiting apparent molar volume $\left(\varphi_{\mathrm{v}}^{\circ}\right)$ have been calculated to explain the interaction. $\varphi_{\mathrm{v}}$ can be defined as the summation of volume of the central solute molecule and changes in the solvent volume as a result of interaction of the solute around its co-sphere. ${ }^{21}$ The TTP forms a ternary solution system with aqueous CD molecules. Here TTP acts as solute and the CD plays the role of co-solvent. $\varphi_{\mathrm{v}}^{\circ}$ illustrates the interaction between them in the following system. $\varphi_{\mathrm{v}}$ values have been determined from the solvent density (measured at $298.15 \mathrm{~K}$ ) (Table S3 $\dagger$ ) using eqn (S5)† as mentioned in ESI (Table S6 $\dagger$ ). $\varphi_{\mathrm{v}}^{\circ}$ 


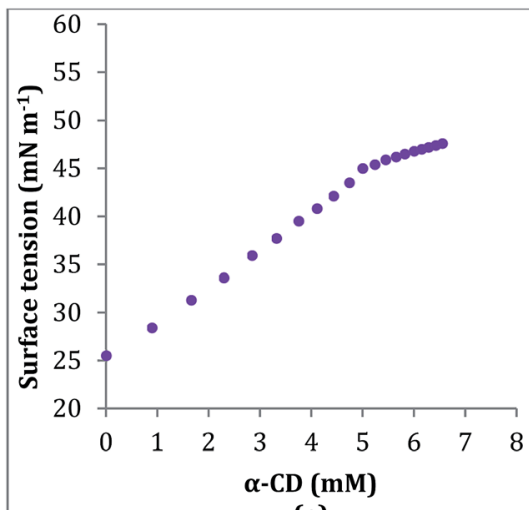

(a)

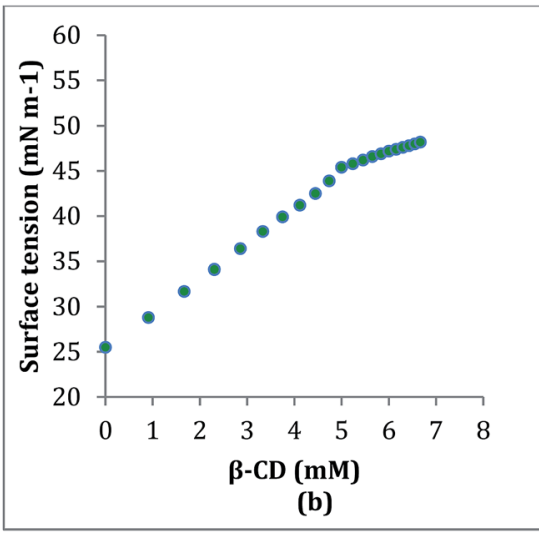

Fig. 3 Variation of surface tension of aqueous TTP solution with increasing concentration of (a) $\alpha-C D$ (b) $\beta$-CD respectively at 298.15 K.

Table 1 Values of surface tension $(\gamma)$ and conductance $(\kappa)$ data the break point with corresponding concentration of $\alpha$ and $\beta-C D$ at $298.15 \mathrm{~K}$

\begin{tabular}{|c|c|c|c|}
\hline \multicolumn{4}{|l|}{ TTP } \\
\hline \multicolumn{2}{|l|}{$\alpha-\mathrm{CD}$} & \multicolumn{2}{|l|}{$\beta-\mathrm{CD}$} \\
\hline \multicolumn{4}{|l|}{ Surface tension } \\
\hline $\begin{array}{l}\text { Concentration } \\
(\mathrm{mM})\end{array}$ & $\gamma \mathrm{mN} \mathrm{m}^{-1}$ & $\begin{array}{l}\text { Concentration } \\
(\mathrm{mM})\end{array}$ & $\gamma \mathrm{mN} \mathrm{m}^{-1}$ \\
\hline 5.30 & 45.57 & 5.24 & 45.84 \\
\hline \multicolumn{4}{|l|}{ Conductivity } \\
\hline $\begin{array}{l}\text { Concentration } \\
(\mathrm{mM})\end{array}$ & $\kappa \mathrm{mS} \mathrm{m}^{-1}$ & $\begin{array}{l}\text { Concentration } \\
(\mathrm{mM})\end{array}$ & $\kappa \mathrm{mS} \mathrm{m}^{-1}$ \\
\hline 4.97 & 2.59 & 4.95 & 2.56 \\
\hline
\end{tabular}

values were calculated by applying least square treatments to the plots of $\varphi_{\mathrm{v}}$ versus $\sqrt{ } m$ with the help of Masson eqn (ESI (S6)†). ${ }^{22,23}$ The limiting apparent molar volumes are depicted in Fig. 5. $\varphi_{\mathrm{v}}$ and $\varphi_{\mathrm{v}}^{\circ}$ values shows decreasing and increasing trend respectively for TTP with the increase of concentration of CD molecules. This trend clearly indicates that for this ionic liquid the ionhydrophilic group interactions are more than ion-hydrophobic

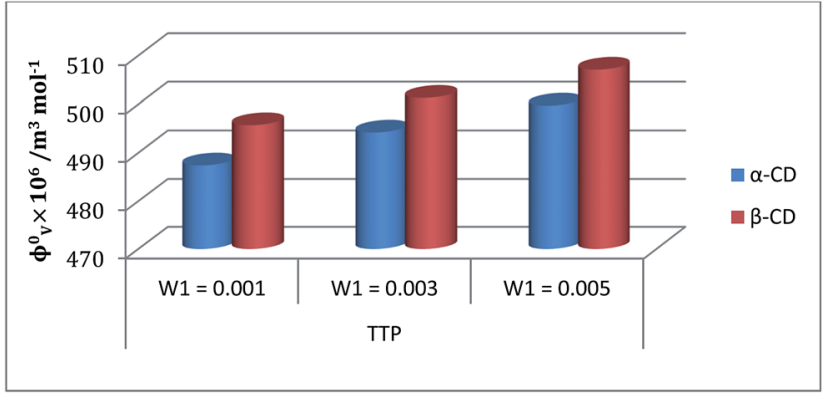

Fig. 5 Plot of limiting molar volume $\left(\varphi_{\mathrm{v}}^{\circ}\right)$ against mass fraction $(w)$ of aqueous $\alpha-C D$ and $\beta-C D$ for TTP ( $\alpha-C D$ blue, $\beta-C D$ brown) at $298.15 \mathrm{~K}$.

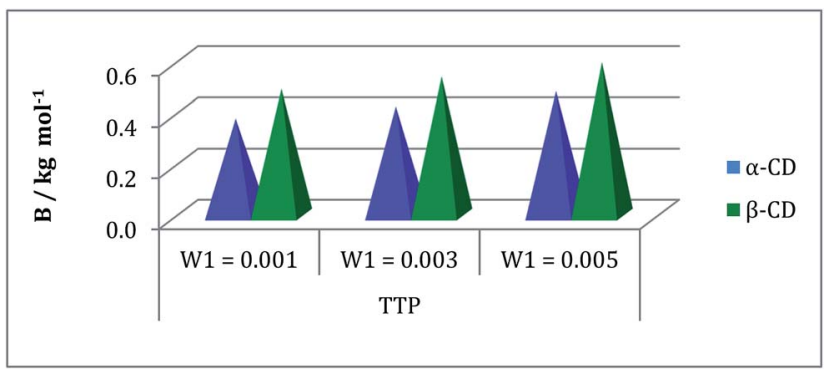

Fig. 6 Plot of viscosity $B$-coefficient against mass fraction $(w)$ of aqueous $\alpha$-CD and aqueous $\beta$-CD for TPP (blue and green respectively) at $298.15 \mathrm{~K}$.

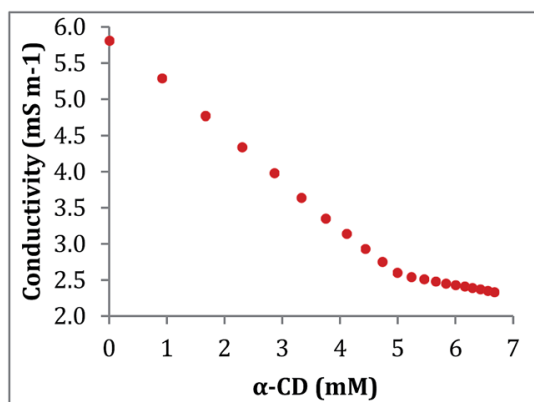

(a)

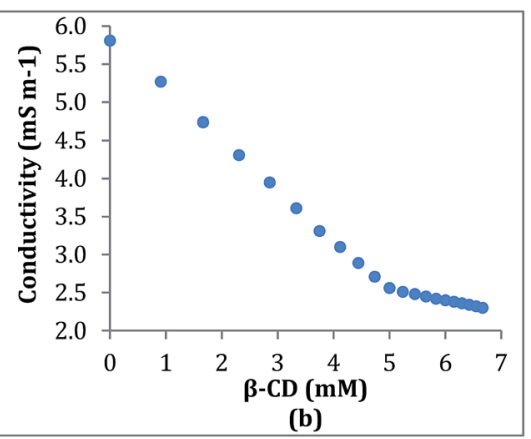

(b)

Fig. 4 Variation of conductivity of aqueous TTP solution with increasing concentration of (a) $\alpha$-CD (b) $\beta$-CD respectively at $298.15 \mathrm{~K}$. 


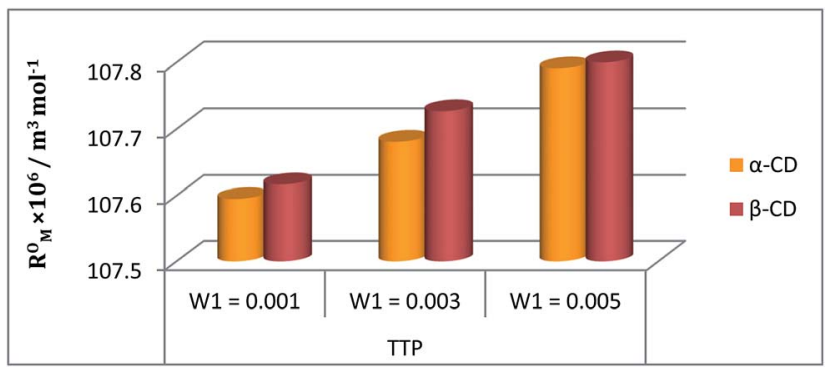

Fig. 7 Plot of limiting molar refraction $\left(R_{\mathrm{M}}^{\circ}\right)$ for TPP in different mass fraction of aqueous $\alpha-C D$ and $\beta-C D$ at $298.15 \mathrm{~K}$.

interactions. The limiting apparent molar volume increases regularly with increasing mass fraction of $\mathrm{CD}$ molecules. The value is slightly higher for $\beta$-CD indicating that it is a better host for TTP. The probable reason behind the assumption is that the hydrocarbon chains are encapsulated in the hydrophobic cavity of host $\mathrm{CD}$ and the positively charged $\mathrm{P}$ atoms interacts with the hydrophilic $-\mathrm{OH}$ groups of the $\mathrm{CD}$ present in the rim. The larger cavity of $\beta$-CD helps to form more stable inclusion complexes with TTP as it contains more number of polar - $\mathrm{OH}$ groups.

\subsection{Viscosity}

The inclusion of the ionic liquid TTP in the CD molecule can be also explained with the help of viscosity study. ${ }^{24,25}$ The viscosity of the solution increases with the increase of the molarity of TTP in this ternary system due to structure making contribution of $\mathrm{CD}$ with water molecules (Table S3†). The viscosity $B$ coefficient have been determined (Table S6 $\dagger$ ) which explains the solute solvent interactions based upon the size and shape of solvent molecules. This parameter is found to be positive and depicted in the Fig. 6 . The rising value of $B$ signifies the increasing interaction of TTP with $\mathrm{CD}$ and higher solvation. ${ }^{21}$ The long hydrophobic decyl chain is encapsulated in the CD cavity. Again the $B$ value is higher for $\beta$-CD than $\alpha$-CD as the former is better host due to larger diameter than the latter. The viscosity result shows similarity with that of density study and it can be concluded that the structure of CDs and TTP are responsible for this kind of interaction.

\subsection{Refractive index}

The refractive index $\left(\eta_{\mathrm{D}}\right)$ also explains the interaction between the ionic liquid TTP with CD molecules. ${ }^{20,21}$ It also supports the data obtained from density and viscosity data. The $\eta_{\mathrm{D}}$ values for a series of solutions are measured (Table S3†) with increasing molarity of
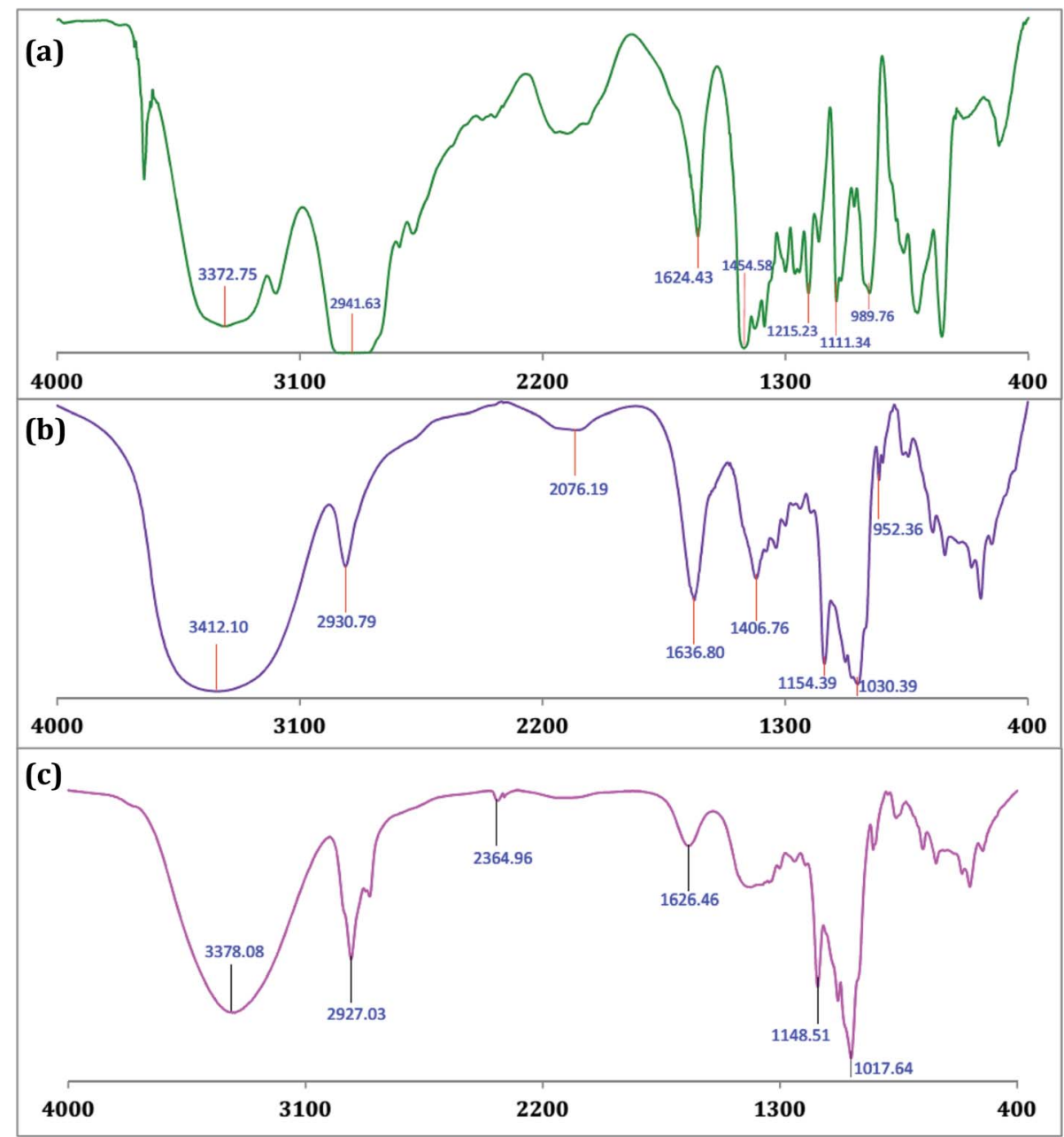

Fig. 8 FTIR spectra of (a) TTP (b) $\alpha-C D$ and (c) TTP- $\alpha-C D$ inclusion complex. 

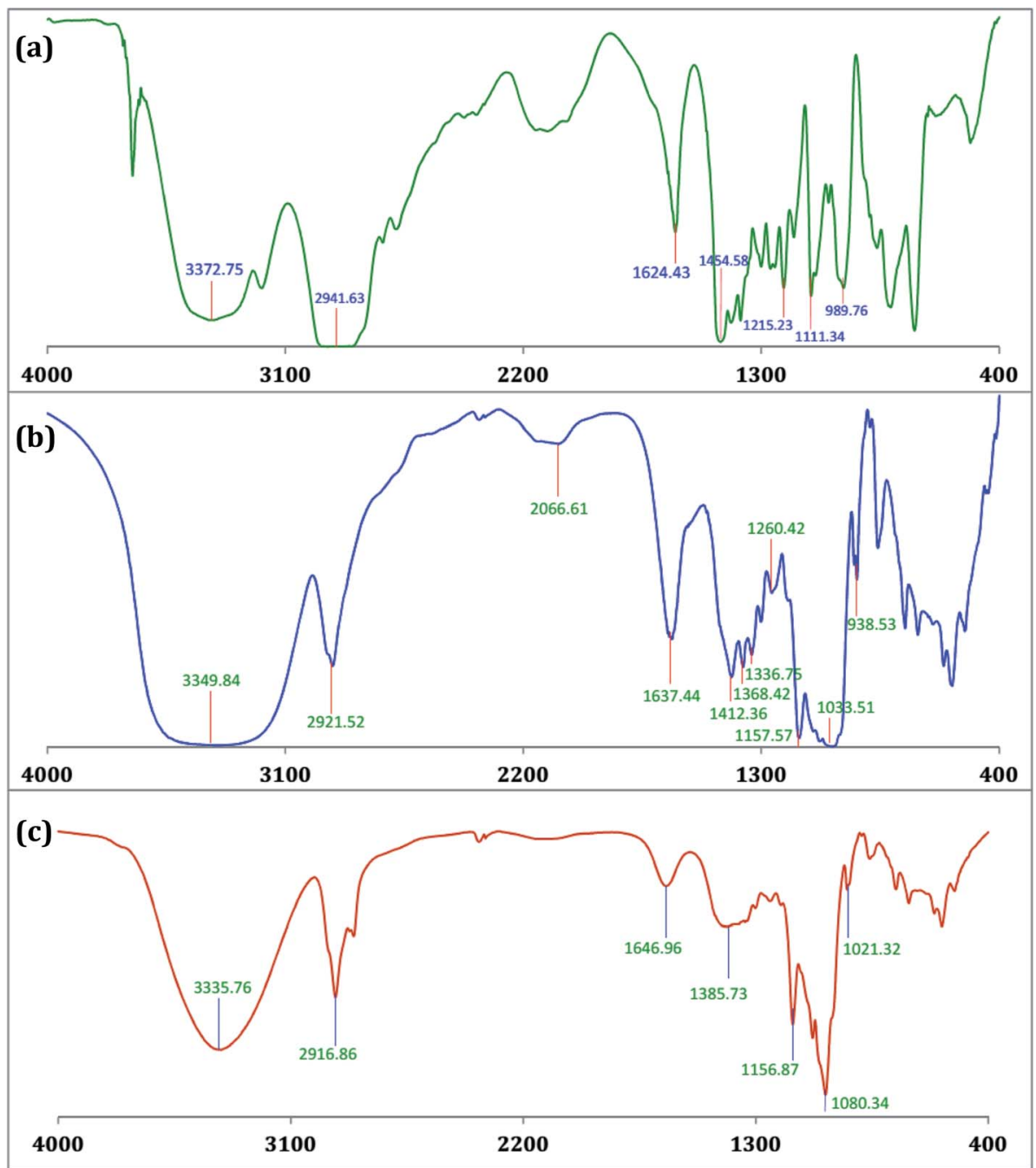

Fig. 9 FTIR spectra of (a) TTP (b) $\beta-C D$ and (c) TTP- $\beta-C D$ inclusion complex.

TTP. The molar refraction $\left(R_{\mathrm{M}}\right)$ and limiting molar refraction $\left(R_{\mathrm{M}}^{\circ}\right)$ of the solutions were also determined using the eqn (S9) and (S10) mentioned in ESI (Table S6). $\uparrow$ The plot (Fig. 7) shows that the $R_{\mathrm{M}}^{\circ}$ value increases with the increase of mass fraction of TTP. The increasing values of both $R_{\mathrm{M}}$ and $R_{\mathrm{M}}^{\circ}$ signify the ternary solution becomes more compact and dense. This means the inclusion complex of TTP with both the CD molecules are closely packed than TTP probably due to greater hydrophobic and ion-hydrophilic interactions. The higher $R_{\mathrm{M}}^{\circ}$ value for $\beta$-CD illustrates that it can better accommodate the ionic liquid in comparison to $\alpha$-CD.

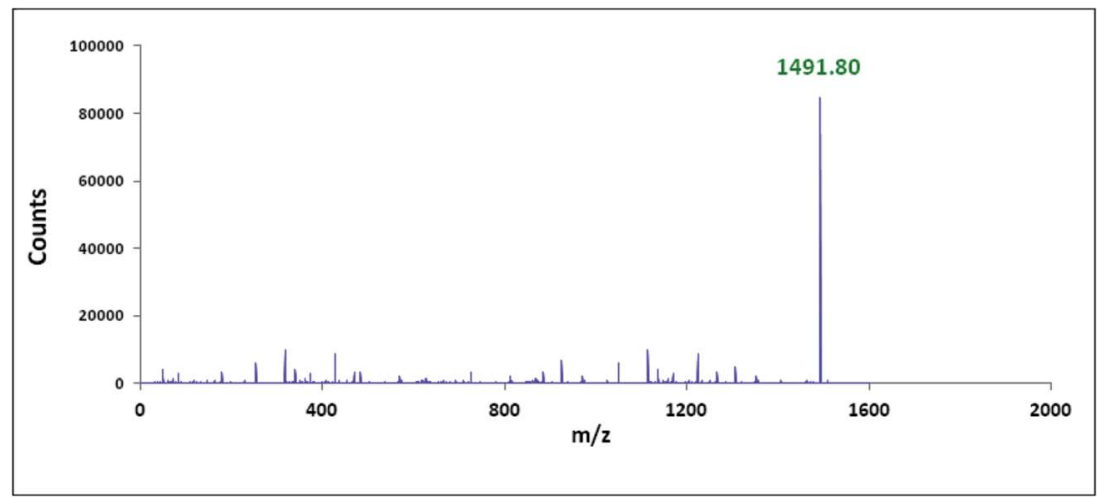

Fig. 10 ESI mass spectra of TTP- $\alpha-C D$ inclusion complex. 


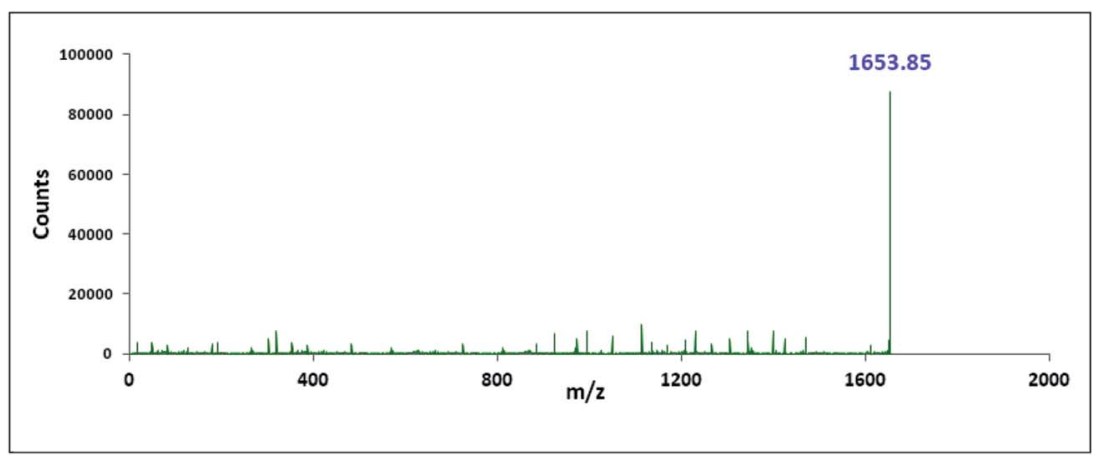

Fig. 11 ESI mass spectra of TTP- $\beta-C D$ inclusion complex.

\subsection{FTIR spectra}

The encapsulation of TTP in the hydrophobic cavity of CD was confirmed from FT-IR spectroscopy as the band resulted from the inserted part of TTP showed a shift or their intensities are changed. ${ }^{26,27}$ FT-IR spectra of TTP, $\alpha$-CD, $\beta$-CD and the inclusion complexes were represented in Fig. 8 and 9. The various frequencies of the above mentioned compounds are reported in Table S8. $\dagger$ The IR spectrum of the ionic liquid can be characterized by principal absorption peaks at 3372.75 (symmetrical stretching of $-\mathrm{C}-\mathrm{H}$ from $\mathrm{CH}_{3}$ ), 2941.63 (symmetrical stretching of $-\mathrm{C}-\mathrm{H}$ from $-\mathrm{CH}_{2}$ ), 1454.58 (stretching of $\mathrm{P}-\mathrm{CH}_{2}-$ ) etc. The broad $-\mathrm{O}-\mathrm{H}$ stretching frequency for $\alpha-\mathrm{CD}$ and $\beta-\mathrm{CD}$ was observed at 3412.10 and $3349.84 \mathrm{~cm}^{-1}$ respectively. In the two IC's the $-\mathrm{O}-\mathrm{H}$ frequency shifted to lower region i.e.; 3378.08 and $3335.76 \mathrm{~cm}^{-1}$ for $\alpha-\mathrm{CD}$ and $\beta-\mathrm{CD}$ respectively. The reason behind the fact is the involvement of the $-\mathrm{O}-\mathrm{H}$ groups of both the CDs in hydrogen bonding with the guest TTP molecule. ${ }^{28,29}$ The prominent peaks of the ionic liquid for $-\mathrm{P}-\mathrm{CH}_{2},-\mathrm{CH}_{3}$, $-\mathrm{CH}_{2}-$ of the hydrocarbon chains are shifted in both the IC's. The changes in the FT-IR spectra of TTP are due to the

Table 2 Binding constants $\left(K_{b}\right)$ of various ionic liquid-cyclodextrin inclusion complexes from conductivity study

\begin{tabular}{lll}
\hline Binding constant ${ }^{b} K_{\mathrm{b}} \times 10^{-3} / \mathrm{M}^{-1}$ & \\
\hline Temperature $^{a} / \mathrm{K}$ & TTP- $\alpha$-CD & TTP- $\beta$-CD \\
\hline 293.15 & 2.35 & 2.47 \\
298.15 & 2.14 & 2.27 \\
303.15 & 1.98 & 2.02
\end{tabular}

${ }^{a}$ Standard uncertainties in temperature $u$ are: $u(T)= \pm 0.01 \mathrm{~K} .{ }^{b}$ Mean errors in $K_{\mathrm{b}}= \pm 0.01 \times 10^{-3} \mathrm{M}^{-1}$.

Table 3 Binding constants $\left(K_{\mathrm{b}}^{*}\right)$ of various ionic liquid-cyclodextrin inclusion complexes from NMR study at $298 \mathrm{~K}$

\begin{tabular}{ll}
\hline $\begin{array}{l}\text { Inclusion } \\
\text { complex }\end{array}$ & Binding constant, $K_{\mathrm{b}}^{*} \times 10^{-3} / \mathrm{M}^{-1}$ \\
\hline TTP- $\alpha$-CD & 2.16 \\
TTP- $\beta$-CD & 2.30
\end{tabular}

restriction of the vibration of free TTP molecules as the hydrocarbon chains are inserted in the cavity of CD molecules. No additional peaks are obtained in the spectra of IC's. This fact again suggests that only non covalent interaction exsists between the CD and TTP, only van der Waal's interaction are present. ${ }^{30,31}$

\subsection{HRMS study}

The characterisation of the two inclusion complexes can also be done by ESI-MS study. ${ }^{32,33}$ Although it is difficult to interpret sometimes but $\mathrm{m} / \mathrm{z}$ value helps to characterise the inclusion complexes formed. Fig. 10 and 11 shows the MS spectra of the two inclusion complexes TTP $+\alpha-\mathrm{CD}$, TTP $+\beta-\mathrm{CD}$ respectively. The intense peaks at $m / z 1491.80$ and 1653.85 indicates the proton adduct of TTP- $\alpha$-CD IC and TTP- $\beta$-CD IC. No other significant peaks are observed at higher values. This study confirms the formation of two inclusion complexes with $1: 1$ stoichiometry. ${ }^{34,35}$

\subsection{Binding constants: non linear isotherms}

Association constants $\left(K_{\mathrm{b}}\right)$ of the two inclusion complexes have been determined from conductivity study. ${ }^{25}$ The insertion of the ionic liquid molecule into the hydrophobic cavity of the two CD molecule results the change in conductivity of the aqueous solution. A non linear programme was used to determine the binding constants depending upon this fact. ${ }^{36,37}$ There exsists an equilibrium between guest TTP and host CD molecules leading to the formation of $1: 1$ inclusion complex. The equilibrium can be represented as

$$
\mathrm{TTP}_{\mathrm{f}}+\mathrm{CD}_{\mathrm{f}} \stackrel{K_{\mathrm{b}}}{\rightleftharpoons} \mathrm{IC}
$$

The expression of the binding constant can be obtained from the above equation as

$$
K_{\mathrm{b}}=\frac{[\mathrm{IC}]}{[\mathrm{TTP}]_{\mathrm{f}}[\mathrm{CD}]_{\mathrm{f}}}
$$

In the above equation, $[\mathrm{IC}],[\mathrm{TTP}]_{\mathrm{f}}$ and $[\mathrm{CD}]_{\mathrm{f}}$ express the equilibrium concentration of the inclusion complex, free TTP 
and cyclodextrin molecule respectively. The binding constant $K_{\mathrm{b}}$ can be expressed in terms of conductivity $\kappa$ as

$$
K_{\mathrm{b}}=\frac{[\mathrm{IC}]}{[\mathrm{TTP}]_{\mathrm{f}}[\mathrm{CD}]_{\mathrm{f}}}=\frac{\left(\kappa_{\mathrm{obs}}-\kappa_{\mathrm{o}}\right)}{\left(\kappa-\kappa_{\mathrm{obs}}\right)[\mathrm{CD}]_{\mathrm{f}}}
$$

where,

$$
[\mathrm{CD}]_{\mathrm{f}}=[\mathrm{CD}]_{\mathrm{ad}}-\frac{[\mathrm{TTP}]_{\mathrm{ad}}\left(\kappa_{\mathrm{obs}}-\kappa_{\mathrm{o}}\right)}{\left(\kappa-\kappa_{\mathrm{o}}\right)}
$$

where $\kappa_{\mathrm{o}}, \kappa_{\mathrm{obs}}$ and $\kappa$ represent the conductivity of TTP initially, during addition of host and final state respectively. [TTP $]_{\mathrm{ad}}$ and $[\mathrm{CD}]_{\mathrm{ad}}$ are the concentrations of IL and the added CD respectively. Application of the non linear programme to the binding isotherms gives the value of $K_{\mathrm{b}}$ (Table 2). The association constant for TTP is slightly higher in case of $\beta$-CD probably due to the reason that it can better accommodate the ionic liquid due to its more larger dimension compared to $\alpha$-CD.

Binding constants $\left(K_{\mathrm{b}}^{*}\right)$ of the two inclusion complexes have also been calculated by similar process from NMR shifts of the CD proton signals upon addition of TTP in the $\mathrm{D}_{2} \mathrm{O}$ solution at $298 \mathrm{~K}$ and shown in Table $3 .{ }^{21}$ These data are comparable with that found form conductivity studies. Here also the binding constant for $\beta$-CD is higher than $\alpha$-CD, confirming that $\beta$-CD can better encapsulate TTP due to its similar sized cavity compared to $\alpha$-CD.

\section{Conclusion}

The present article confirms that the above mentioned ionic liquid trihexyltetradecylphosphonium chloride forms inclusion complex with both $\alpha$ and $\beta$-CD in aqueous medium and in solid state. These two ICs can be used for controlled release of this ionic liquid. ${ }^{1} \mathrm{H}$-NMR study confirms the inclusion phenomenon whereas surface tension and conductivity study reveal the 1:1 stoichiometry of the complexes. Density, viscosity and refractive index study show the interaction between the guest and host CDs. FT-IR spectra and mass spectra also supported the formation of IC. The binding constants for the formation of the two ICs have been evaluated from non linear isotherms using conductivity and NMR studies. It is found to be higher for $\beta$-CD. These two ICs have application in various industrial processes to make them greener.

\section{Experimental section}

\subsection{Source and purity of samples}

Trihexyltetradecylphosphonium chloride, $\alpha$-cyclodextrin and $\beta$ cyclodextrin of puriss grade were bought from Sigma-Aldrich, Germany. The chemicals are used in the experiment in the same condition as purchased. The mass fraction purity of TTP, $\alpha$-cyclodextrin and $\beta$-cyclodextrin are $\geq 0.98, \geq 0.99$ and $\geq 0.98$ respectively.

\subsection{Apparatus and procedure}

The above mentioned ionic liquid trihexyltetradecylphosphonium chloride and the two CDs are freely soluble in triply distilled, deionized and degassed water. The stock solutions of TTP and aqueous CD were prepared by mass at $298.15 \mathrm{~K}$. Mettler Toledo AG-285 (uncertainty $0.0001 \mathrm{~g}$ ) was used for weighing.

${ }^{1} \mathrm{H}$ NMR spectra were taken in $\mathrm{D}_{2} \mathrm{O}$ at $300 \mathrm{MHz}$ with help of Bruker Advance instrument at $298.15 \mathrm{~K}$. Signals are mentioned as $\delta$ values in $\mathrm{ppm}$. The internal standard is $\mathrm{D}_{2} \mathrm{O}$ (protonated signal at $4.79 \mathrm{ppm})$. Data are cited as chemical shift.

The surface tension study was performed with platinum ring detachment technique using a Tensiometer (K9, KRSS; Germany). The temperature is maintained at $298.15 \mathrm{~K}$ by circulation of thermostated water through a double wall glass vessel containing the solution. The accuracy of the instrument is about $\pm 0.1 \mathrm{mN} \mathrm{m}^{-1}$.

The conductivity study was carried out using a Mettler Toledo Seven Multi conductivity meter (uncertainty $\pm 1.0 \mu \mathrm{S} \mathrm{m} \mathrm{m}^{-1}$ ) in a thermostated water bath at $298.15 \mathrm{~K}$. HPLC grade water was used with a specific conductance of $6.0 \mathrm{mS} \mathrm{m}^{-1}$. Calibration of the conductivity cell was done with $0.01 \mathrm{M}$ aqueous $\mathrm{KCl}$ solution. Uncertainty of temperature was $\pm 0.01 \mathrm{~K}$.

The densities $(\rho)$ of the series of solutions were measured by vibrating U-tube Anton Paar digital density meter (DMA $4500 \mathrm{M}$ ) (precision $\pm 0.00005 \mathrm{~g} \mathrm{~cm}^{-3}$ ). Calibration of the density meter was carried out by standard method. Uncertainty of temperature was $\pm 0.01 \mathrm{~K}$.

The viscosities $(\eta)$ of the solutions are measured with Brookfield DV-III Ultra Programmable Rheometer (spindle size 42). Other information has already mentioned.

Digital Refractometer from Mettler Toledo has been used to measure the refractive index of the solutions (uncertainty \pm 0.0002 units). Other information has already mentioned.

The two inclusion complexes of the ionic liquid TTP with both CD molecules (TTP $+\alpha$-CD, TTP $+\beta$-CD) have been prepared in $1: 1$ molar ratio. $1.0 \mathrm{mmol} \alpha-\mathrm{CD}$ and $1.0 \mathrm{mmol}$ TTP were separately dissolved in $30 \mathrm{ml}$ water. The two solutions were separately stirred for 4 hours. Then the aqueous solution of the TTP was drop wise added to aqueous $\alpha$-CD solution. The mixture is stirred for 72 hours at about $60^{\circ} \mathrm{C}$. The solution is filtered at $60{ }^{\circ} \mathrm{C}$ and allowed to cool to $10^{\circ} \mathrm{C}$. It was kept for 12 hours. After that the suspension was filtered and white crystalline powder was found. It was washed with ethanol and dried in air.

The solid inclusion complexes are dissolved in methanol. HRMS spectra were recorded with a Q-TOF high resolution instrument by positive mode electro-spray ionization.

FTIR spectra were taken by Perkin Elmer FTIR spectrometer by $\mathrm{KBr}$ disk technique. For preparation of $\mathrm{KBr}$ disk $1 \mathrm{mg}$ of the solid inclusion complex and $100 \mathrm{mg} \mathrm{KBr}$ were mixed. The scanning range of the spectra is $4000-400 \mathrm{~cm}^{-1}$ at room temperature.

\section{Conflicts of interest}

The authors declare that they have no conflict of interest.

\section{Acknowledgements}

The authors are thankful to the special assistance scheme, Department of Chemistry, University of North Bengal under 
UGC, New Delhi for financial assistance and providing instruments to carry out the research work. Prof. M. N. Roy was also highly obliged to University Grants Commission, New Delhi, Government of India, for being awarded one time grant under basic scientific research.

\section{References}

1 Z. Ullah, M. A. Bustam, Z. Man and A. S. Khan, ARPN J. Eng. Appl. Sci., 2016, 3, 11.

2 G. Flamini, B. Melai, L. Pistelli and C. Chiappe, RSC Adv., 2015, 5, 69894.

3 S. Zhang, J. Sun, X. Zhang, J. Xin, Q. Miao and J. Wang, Chem. Soc. Rev., 2014, 43, 7338.

4 D. C. Gonzalez, M. A. Rodriguez, G. Cote and A. Chagnes, J. Mol. Liq., 2013, 187, 165-170.

5 N. Rajendiran and S. Siva, Carbohydr. Polym., 2014, 101, 828836.

6 Z. Aytac, H. S. Sen, E. Durgun and T. Uyar, Colloids Surf., B, 2015, 128, 331-338.

7 B. Dutta, S. Barman and M. N. Roy, J. Mol. Liq., 2016, 214, 264-269.

8 B. Wei, Carbohydr. Polym., 2015, 134, 398-405.

9 A. D. Bani-Yaseen and A. Mo'ala, Spectrochim. Acta, Part A, 2014, 131, 424-431.

10 L. Wang, S. Li, P. Tang, J. Yan, K. Xu and H. Li, Carbohydr. Polym., 2015, 129, 9-16.

11 S. Saha, T. Ray, S. Basak and M. N. Roy, New J. Chem., 2016, 40, 651-661.

12 T. Wang, M. D. Wang, C. Ding and J. Fu, Chem. Commun., 2014, 50, 12469-12472.

13 M. N. Roy, S. Saha, S. Barman and D. Ekka, RSC Adv., 2016, 6, 8881-8891.

14 Y. Gao, X. Zhao, B. Dong, L. Zheng, N. Li and S. Zhang, J. Phys. Chem. B, 2006, 110, 8576-8581.

15 M. N. Roy, D. Ekka, S. Saha and M. C. Roy, $R S C A d v ., 2014,4$, 42383-42390.

16 A. Pineiro, X. Banquy, S. P. Casas, E. Tovar, A. Garcia, A. Villa, A. Amigo, A. E. Mark and M. Costas, J. Phys. Chem. B, 2007, 111, 4383-4392.

17 Y. Gao, Z. Li, J. Du, B. Han, G. Li, W. Hou, D. Shen, L. Zheng and G. Zhang, Chem.-Eur. J., 2005, 11, 5875-5880.
18 A. Apelblat, E. Manzurola and Z. Orekhova, J. Solution Chem., 2007, 36, 891-900.

19 T. Qian, C. Yu, S. Wu and J. Shen, Colloids Surf., B, 2013, 112, 310-314.

20 A. Roy, S. Saha and M. N. Roy, Fluid Phase Equilib., 2016, 425, 252-258.

21 M. N. Roy, A. Roy and S. Saha, Carbohydr. Polym., 2016, 151, 458-466.

22 D. Ekka and M. N. Roy, RSC Adv., 2014, 4, 19831-19845.

23 D. O. Masson, Philos. Mag., 1929, 8, 218-223.

24 M. N. Roy, D. Ekka, S. Saha and M. C. Roy, RSC Adv., 2014, 4, 42383-42390.

25 A. Roy, S. Saha, B. Datta and M. N. Roy, RSC Adv., 2016, 6, 100016.

26 C. Xiao, K. Li, R. Huanga, G. Hea, J. Zhang, L. Zhu, Q. Yang, K. Jiang, Y. Jin and J. Lin, Carbohydr. Polym., 2014, 102, 297305.

27 T. Stalin, K. Srinivasan, K. Sivakumar and S. Radhakrishnan, Carbohydr. Polym., 2014, 107, 72-84.

28 K. Sivakumar, T. R. Ragi, D. Prema and T. Stalin, J. Mol. Liq., 2016, 218, 538-548.

29 W. Misiuk and M. Jozefowicz, J. Mol. Liq., 2015, 202, 101106.

30 N. Rajendiran and S. Siva, Carbohydr. Polym., 2014, 101, 828836.

31 N. Rajendiran, G. Venkatesh and T. Mohandass, Spectrochim. Acta, Part A, 2014, 123, 158-166.

32 J. Zhang, K. Jiang, K. An, S. Ren, X. Xie, Y. Jin and J. Lin, Carbohydr. Res., 2015, 418, 20-28.

33 Y. Okada, K. Ueyama, J. Nishikawa, M. Semma and A. Ichikawa, Carbohydr. Res., 2012, 357, 68-74.

34 M. Ceborska, M. Zimnicka, M. Wszelaka-Rylik and A. Troc, J. Mol. Struct., 2016, 1109, 114-118.

35 Z. Szabó, G. Tóth, G. Völgyi, B. Komjáti, G. Hancu, L. Szente, T. Sohajda, S. Béni, D. L. Muntean and B. Noszál, J. Pharm. Biomed. Anal., 2016, 117, 398-404.

36 P. Thordarson, Chem. Soc. Rev., 2011, 40, 1305-1323.

37 M. A. Spies and R. L. Schowen, J. Am. Chem. Soc., 2002, 124, 14049-14053. 